\title{
LETTERS
}

\section{Surgery for obstructive sleep apnea}

We read with interest the piece by Laratta and colleagues ${ }^{1}$ regarding diagnosis and treatment of obstructive sleep apnea in adults. The authors are to be commended for the thoughtfulness of their work.

However, we are concerned by several important omissions from this piece. First, although the authors point out the strong historical advantages to continuous positive airway pressure (CPAP), they surprisingly neglected to inform the readership of the dismal rate of long-term CPAP adherence, which has been well studied in large populations and found to be less than $50 \%$ after one year of prescription. This places the concept of CPAP as the gold standard for obstructive sleep apnea therapy under some doubt. Second, in reference to surgery for sleep apnea, the authors mention only various older forms of surgery, some of which have not been done for years. Surgery for sleep apnea has been studied extensively in recent years, because, in parallel with the poor uptake of CPAP, patients are looking for more permanent solutions, and thus techniques have been devised to improve surgical success. The modern scientific literature shows a number of far more advanced techniques than those the authors refer to that carry a success rate comparable to CPAP. ${ }^{2}$ Finally, no discussion on treatment can be had in the modern era without reference to value and cost, in which case contemporary data would suggest that surgery is comparable to CPAP. ${ }^{3}$

This article has missed an important segment of the literature and presents an incomplete picture of the management of this complex disease.

\section{Brian Rotenberg MD}

Otolaryngology-head and neck surgery, Schulich School of Medicine \& Dentistry, Western University, London, Ont.

\section{Kenny Pang MD}

Otolaryngology-head and neck surgery, Asia Sleep Centre, Paragon, Singapore

- Cite as: CMAJ 2018 April 9;190:E444. doi: 10.1503/cmaj.69114

\section{References}

1. Laratta CR, Ayas NT, Povitz M, et al. Diagnosis and treatment of obstructive sleep apnea in adults. CMAJ 2017;189:E1481-8.

2. Rashwan MS, Montevecchi F, Cammaroto G, et al. Evolution of soft palate surgery techniques for obstructive sleep apnea patients: a comparative study for single-level palatal surgeries. Clin Otolaryngol 2018;43:584-90.

3. Rotenberg BW, Vicini C, Pang EB, et al. Reconsidering first-line treatment for obstructive sleep apnea: a systematic review of the literature. J Otolaryngol Head Neck Surg 2016;45:23.

Competing interests: None declared. 